\title{
PROPOSTA DE IMPLEMENTAÇÃO DE DESENVOLVIMENTO PESSOAL COMO FATOR MOTIVACIONAL: ESTUDO DE CASO MDA ELEVADORES
}

\section{ARTIGO ORIGINAL}

ALBARADO, Jasmin de Moura ${ }^{1}$, MARTINS, Jailla Regina Gonçalves², DOCE, Vitória Isabelle Leite ${ }^{3}$, ALMEIDA, Victor da Silva $^{4}$, ROBERTO, José Carlos Alves ${ }^{5}$

ALBARADO, Jasmin de Moura. Et al. Proposta de implementação de desenvolvimento pessoal como fator motivacional: estudo de caso MDA Elevadores. Revista Científica Multidisciplinar Núcleo do Conhecimento. Ano. 06, Ed. 11, Vol. 11, pp. 27-50. Novembro 2021. ISSN: 2448-0959, Link de acesso: https://www.nucleodoconhecimento.com.br/administracao/fator-motivacional, DOI: 10.32749/nucleodoconhecimento.com.br/administracao/fator-motivacional

\section{RESUMO}

O artigo teve como propósito realizar um estudo de caso na organização M.D.A Elevadores, que atua no comércio industrial de produto/serviço. A empresa se encaixa na categoria pequeno porte que comercializa elevadores, escadas rolantes e transportes verticais. O estudo deu início a partir do diagnóstico organizacional realizado na empresa onde se analisou as áreas funcionais da organização por meio de coleta de dados. Foram identificadas fragilidades na área de recursos humanos principalmente no desenvolvimento de pessoal e motivação das equipes. A partir do contexto abordado, este estudo pretende responder: Como o processo de desenvolvimento pessoal pode contribuir com a melhoria da motivação das equipes

\footnotetext{
${ }^{1}$ Graduanda do curso de Administração.

${ }^{2}$ Graduanda do curso de Administração.

${ }^{3}$ Graduando do curso de Administração.

${ }^{4}$ Coorientador. Mestrado em Engenharia de processos. Pós-graduando em Neuropsicopedagogia Institucional. Especialização em Gestão Estratégica de RH. Graduação em Administração e Pedagogia.

${ }^{5}$ Orientador. Mestrado profissional em Engenharia de Produção. Especialização em Gestão em Logística empresarial. Graduação em Administração com ênfase em Marketing.
}

RC: 101786

Disponível em: https://www.nucleodoconhecimento.com.br/administracao/fatormotivacional 
funcionais? O objetivo geral consistiu-se em compreender como o processo de desenvolvimento pessoal pode cooperar com a melhoria da motivação das equipes funcionais. A metodologia adotada foi de revisão bibliográfica, pesquisa qualitativa e de natureza aplicativa. Como resultados elaborou-se uma proposta com ações interventivas focadas no desenvolvimento das equipes por meio da introdução de treinamentos, mapeamento as atividades produtivas eliminando os gargalos e retrabalhos, melhoria no atendimento ao cliente, além de estabelecer parceiras estratégicas com fornecedores de suprimentos. Para nortear estas atividades utilizou-se a ferramenta $5 \mathrm{~W} 2 \mathrm{H}$ a fim de controlar as etapas interventivas. Por meio das ações propostas, a empresa deve atingir o aperfeiçoamento do processo, proporcionando incrementos na motivação do pessoal e aumento da produtividade na execução dos serviços, fortalecendo a marca, consolidando a empresa no mercado, melhorando o clima organizacional, reduzindo os gastos do processo de produção e maximizando lucros, além de reter talentos.

Palavras-chaves: Desenvolvimento Pessoal, Motivação, Treinamento, Recursos Humanos.

\section{INTRODUÇÃO}

O artigo refere-se a um estudo de caso realizado na organização MDA Elevadores atuante no Comércio Industrial de produtos e serviços, a empresa é de pequeno porte que negocia e vende elevadores, escadas rolantes, e transportes verticais.

Dentro de um âmbito cada vez mais competidor, junto a exigência da produtividade máxima, o ser humano assume enorme pertinência dentro do meio corporativo, sendo este agente fundamental do meio, sendo chave fundamental no alcance das metas traçadas pela organização. Apesar disto, a motivação humana e o desenvolvimento pessoal ainda são um desafio dentro das organizações, inclusive na empresa estudada, onde foi diagnosticado a área de recursos humanos como a área funcional que apresentou o pior desempenho. Desse modo, o objetivo geral 
baseia-se em compreender como o processo de desenvolvimento pessoal pode contribuir com o aprimoramento do estímulo das equipes funcionais.

Para a realização de um estudo de caso se faz necessário um direcionamento, logo, durante a execução do diagnóstico e análise foi notório a necessidade de compreender: como o processo de desenvolvimento pessoal pode contribuir com a melhoria da motivação das equipes funcionais?

Neste contexto, a metodologia adotada foi de revisão bibliográfica pesquisa qualitativa e de natureza aplicativa tendo em vista que foram utilizadas como meios para elaboração de um planejamento de interferência. $\mathrm{Na}$ atual conjuntura, tornou-se indispensável e fundamental focalizar a atenção no aspecto comportamental dos colaboradores, designados como público interno, em razão dos gestores terem que conquistá-los, em consequência de atingir a satisfação dos funcionários e obterem sucesso nos processos da organização. O alcance dessa satisfação é de suma importância pois proporciona uma boa relação da organização juntamente com o mercado na qual está inserida, dado que são os funcionários que caracterizam a instituição em negociações com fornecedores e o público externo.

Diante da problemática tornou-se indispensável estudar afundo os principais pilares da motivação humana dentro das organizações além de interpretar como a produtividade e a motivação estão ligadas pelas suas premissas. Neste sentido, o desenvolvimento pessoal tornou-se ferramenta chave para proposta de intervenção, consequentemente a ferramenta interventora adotada foi a $5 \mathrm{~W} 2 \mathrm{H}$, um instrumento estratégico e norteadora de atividades, foi utilizada para efetivar treinamentos, mapear as atividades produtivas reduzindo gargalos, aperfeiçoamento no atendimento ao cliente, elevando o conhecimento técnico da equipe funcional proporcionando melhora na tomada de decisão além de estabelecer parcerias estratégicas com fornecedores de suprimentos e por meio destas ações viabilizar o aumento da motivação e em consequência impactando no aumento da produtividade, fortalecimento da marca, consolidação no mercado, melhora do clima 
organizacional, redução dos custos do processo produtivo e maximização dos lucros, além de reter talentos.

\section{FUNDAMENTAÇÃO TEÓRICA}

A revisão bibliográfica consiste em uma vasta pesquisa de estudos realizados para averiguar a pergunta problema deste artigo científico com o objetivo de adquirir mais conhecimento.

A fundamentação teórica teve como base dissertações, livros e artigos com a finalidade dos pesquisadores tornem-se aptos para obter em grau superior mais conhecimento a respeito da temática proposta nesta obra e assim retirar citações para opulentar e fundamentar a pesquisa.

\subsection{DESENVOLVIMENTO PESSOAL}

Conforme os preclaros De Lara e Rosa (2015), a descentralização nos processos de Recursos Humanos tem notória relação quanto ao desenvolvimento dos colaboradores, ao passo que desanuvia a sobrecarga de tarefas organizacionais deste setor, promovendo a desburocratização de processos para que se possa focar em outras atividades inerentes à função, promovendo, nas palavras dos autores: "um setor mais efetivo e atuante".

Ainda sobre o que dispõem De Lara e Rosa (2015), este hodierno processo de desburocratizar procedimentos é corolário da necessidade de evolução dos processos de modo a acompanhar a tendência evolutiva humana. Deixou-se de lado então o antigo paradigma de prestigiar tão somente a área burocrática, mas sim passando a dar ênfase na principal força motriz de qualquer organização: $O$ colaborador.

A questão do desenvolvimento pessoal pauta-se, principalmente, na possibilidade de acompanhamento do desempenho daquele colaborador por seu gestor imediato, trabalhando com feedbacks de modo a orientá-lo naquilo que pode vir a melhorar em

RC: 101786

Disponível em: https://www.nucleodoconhecimento.com.br/administracao/fatormotivacional 
sua conduta em âmbito organizacional. No estudo de caso promovido por De Lara e Rosa (2015), por exemplo, $85 \%$ dos colaboradores afirmaram ter melhorado seu desenvolvimento após a aplicação de procedimentos de descentralização.

Ainda sobre aquilo que dispõem De Lara e Rosa (2015) é mister enfatizar o acompanhamento do gestor. Entretanto, salienta-se mais um aspecto do desenvolvimento pessoal: $O$ desenvolvimento de competências do colaborador. Pauta-se principalmente, em aplicação de procedimentos metodológicos voltados ao aprendizado efetivo durante o treinamento.

Ainda em matéria de administração de recursos humanos, faz-se necessário apresentar algumas atribuições do setor, enfatizando todos os pontos que teriam significativo ganho com a descentralização de processos, sendo eles a questão do desenvolvimento, do controle e a de avaliação de pessoal (DE LARA E ROSA, 2015)

\subsubsection{DESENVOLVIMENTO PESSOAL E TREINAMENTO COMO ESTRATÉGIA COMPETITIVA}

O desenvolvimento corporativo é a competência de compreender novas aptidões, atingir novos conhecimentos e transformar modos e comportamentos. Neste contexto, uma aptidão concede uma assombrosa expansão da competência profissional de cada indivíduo. A finalidade dos recursos humanos é a relação entre a organização e seus colaboradores. A cultura da organização carece refletir-se no planejamento do seguimento ou na estrutura organizacional, bem como na combinação entre centralização ou descentralização.

Fernandes (2013) afirma que o desenvolvimento de qualquer competência organizacional está vinculado às pessoas. O modo pelo qual os profissionais são gerenciados, inspirados, desenvolvidos, recompensados etc., desempenha papel essencial na configuração da competência organizacional, pois as pessoas são a "alma" da competência da organização.

RC: 101786

Disponível em: https://www.nucleodoconhecimento.com.br/administracao/fatormotivacional 
Neste sentido aperfeiçoar indivíduos não é somente ampliar novas competências e sim o desenvolvimento da aptidão e do desejo de se adequar ao meio organizacional no qual está inserido. Em consequência, as organizações que laboriosamente buscam o progresso de seus colaboradores sobrevivem e alcançam êxito nas atividades desempenhadas. Enquanto, as empresas que não o fazem, geralmente são as primeiras a se dar mal.

Nos dias atuais, o treinamento é notado como um componente indispensável no método de desenvolvimento organizacional e, deste modo, torna-se essencial refletir que, diante de um planeta capitalista, as pessoas transformam-se em uma das maiores fortunas das firmas, apesar de tantas tecnologias (TACHIZAWA, 2015). Diante disso, podemos afirmar que o treinamento é feito dos Recursos Humanos assíduo e que desenvolvimento é um feito mais focado para o futuro do colaborador, do trabalho e da empresa. Além disso, o treinamento é um dos recursos do Desenvolvimento de Pessoal, onde propõe-se o aprimoramento de desempenhos, aumento da produtividade e das relações interpessoais.

Chiavenato (2014) modernamente argumenta que o treinamento é visto como um método de aumentar competências nos indivíduos a fim de que eles se tornem mais lucrativos, criativos e inovadores com a finalidade de colaborar melhor para as metas organizacionais e se tornar progressivamente mais valiosas.

\subsubsection{TREINAMENTO NO MODELO DE MENTORIA CUSTO- BENEFÍCIO E REFORÇO DA CULTURA ORGANIZACIONAL}

Treinamento no modelo de mentoria refere-se a uma atividade unicamente realizada por um profissional habilitado em sua área de execução. Podemos exemplificar, caso empreendedor contém adversidade em sua empresa na parte de recursos humanos pode contratar um mentor com abrangente experiencia na área de atuação de mercado para Ihe dar instruções. Esse profissional, um exemplo de tutor, irá partilhar entendimentos e vivencias para incentivar a promoção da evolução do empreendedor ou individuo em sua nova trajetória.

RC: 101786

Disponível em: https://www.nucleodoconhecimento.com.br/administracao/fator$\underline{\text { motivacional }}$ 
Passmore; Peterson e Freire (2013) definem a mentoria como uma estratégia para o aperfeiçoamento dos indivíduos dentro das organizações, onde se estabelece um relacionamento de orientação que ocorre normalmente de maneira informal entre dois indivíduos com diferentes status no âmbito organizacional.

McLean e Hudson (2012) destacam que o mentoring fornece o embasamento para o coaching, porém através de uma perspectiva mais limitada. Apesar deste fato, as funções desempenhadas entre profissional de coaching, o cliente e o mentor, se distinguem durante o processo. Dessa forma, o mentor habitua ser um profissional bastante preparado e especialista na área qual é atuante e desempenha essa incumbência devido tal expertise. Dessa maneira, a mentoria circunda treinamento hábil.

\subsubsection{ABORDAGEM NAS RELAÇÕES HUMANAS}

Nascida da necessidade de inserir o lado humano e democratizar a administração a escola de relações humanas foi a incumbida por admitir na administração importância da motivação e das necessidades sociais do ser humano na organização. Tendo em vista que as demais escolas, como a clássica e burocrática, focavam no processo e no maquinário. Estabelecido no Homem social, a escola orienta os administradores a motivarem os trabalhadores, propiciando boas condições de trabalho, gerando satisfação. Se na abordagem clássica, a autoridade do líder era concebida em troca de um salário melhor, esta escola, prova que este fator solitário não é suficiente, reforçando a ideia de que a atenção concebida a equipe é um fator chave.

Deste modo, segundo Maximiano (2015), o começo do colégio humanista foi uma crítica à escola clássica da administração e conclusão de pesquisas relacionadas à Psicologia e à Sociologia. A escola humanista da mesma forma discutiu a demanda do rendimento a todo preço, assim como constatou a influência dos sindicatos que batalhavam para maior justiça e condições melhores de serviço nas organizações. 
Contudo, podemos afirmar que a escola das relações humanas ou a abordagem humanística como também é conhecida, contribuiu e influenciou a administração moderna a despertar o seu olhar para outros fatores, como o bem-estar do indivíduo, o clima organizacional, o impacto da motivação dos trabalhadores e claro a influência desses aspectos na produtividade. Foi uma escola inovadora, tendo em vista, que as escolas anteriores, mantinham sua atenção, no homem mecânico, onde o empregado era visto como mais uma máquina dentro do mecanismo produtivo.

\subsubsection{MOTIVAÇÃO}

A palavra motivação descreve a razão por qual o indivíduo mobiliza-se a fazer algo, sobre este assunto o autor Chiavenato (2014), acredita que "é difícil definir exatamente o conceito de motivação, uma vez que tem sido utilizado com diferentes sentidos. De modo geral, motivo é tudo aquilo que impulsiona a pessoa a agir de determinada forma ou, pelo menos, que dá origem a um comportamento específico".

A motivação é determinada como sendo natural, a qual encontra-se no interior de todos e que acontece do exterior para o interior, pois envolve a alegria de fazer, que leva em sua companhia além de resultados a alegria de produzir. A motivação que é dita extrínseca possui base no resultado, é possuir um foco e procurar alcançá-lo, não interessando, necessariamente, as emoções envolvidas e o que necessita ser realizado. "motivação é uma força, uma energia que nos impulsiona na direção de alguma coisa [...] ela nos é, absolutamente, intrínseca, isto é, está dentro de nós, nasce de nossas necessidades interiores". (VERGARA, 2010)

\subsubsection{O IMPACTO DA MOTIVAÇÃO NA PRODUTIVIDADE}

A motivação ainda é uma adversidade para as empresas atualmente devido o mercado está cada vez mais competitivo e globalizado. As organizações estão constantemente a procura de maneiras que propiciem seus funcionários a entregaram o máximo de produtividade. Dentro deste contexto, é importante 
ressaltar a relação entre produtividade e a motivação dos empregados, é possível concluir que a motivação é a chave de uma produtividade alta. Segundo Maximiano (2012) a teoria da expectativa está relacionada ao desempenho e recompensa, pessoas se esforçam para conseguir um resultado satisfatório.

Ainda do autor, ele interpreta os fatores que mais influenciam a satisfação dos funcionários, é fundamental para poder motivá-los a fim de se obter um melhor engajamento por parte destes trabalhadores e consequentemente melhor resultado na produtividade do seu trabalho. (MAXIMIANO, 2015)

Investir em fatores que propiciem estímulos aos funcionários, é um investimento com retorno garantido para a organização possibilitar, dentro desse assunto, Ferreira (2012) afirma que no contexto das organizações, um alinhamento saudável entre as esferas do bem-estar, da eficiência e da eficácia, colocando-as a serviço da missão e dos objetivos organizacionais estabelecidos, o ajuste entre essas duas vertentes, proporcionam enormes vantagens competitivas, levando em consideração os números, uma pessoa motivada pode produzir o dobro do que já produz, deste modo, torna-se mais válido motivar a equipe funcional qual você já conta, a investir na rotatividade ou aumento da equipe. Motivar o colaborador que já faz parte da equipe, apresenta um custo-benefício ótimo e resultados satisfatórios.

A organização que mantém suas equipes funcionais motivadas, apresenta um diferencial competitivo frente ao mercado, tendo equipes motivadas são compostas por colaboradores que produzem, entregam o máximo de produtividade e estão dispostos a aceitar o desafio, de levar a empresa até os seus objetivos e metas traçadas.

\subsubsection{PROGRAMAS DE CAPACITAÇÃO COMO RECONHECIMENTO}

Lorentz (2014) coloca o reconhecimento no trabalho como um dos pilares principais à saúde mental do colaborador, uma vez que o trabalho é parte componente da identidade do indivíduo, influenciando, inclusive, em suas relações interpessoais. 
Conhecida a importância do Reconhecimento enquanto parte da essência humana, é mister perceber como a capacitação influencia nesta questão, exercendo uma relação quase como de causa e efeito.

Ainda sobre a necessidade de realização pessoal, Soares (2015), orienta que "o desejo de atingir seus objetivos, ser reconhecido e valorizado são alguns sinais mais conhecidos que motivam o ser humano".

Vianna (2015) corrobora com aquilo que fora disposto por Lorentz (2014), uma vez que afirma que "o treinamento nas organizações passou a abranger também os aspectos psicossociais dos indivíduos". Depreendidos os conceitos basilares do reconhecimento, é mister ater-se ao elo entre capacitar e obter reconhecimento.

A Associação Empresarial da Região Metropolitana de Florianópolis (2017) bem pontua que "Capacitar é investir em resultados e no sucesso do seu negócio". O reconhecimento enquanto fator corolário do sucesso na realização de suas atividades profissionais é uma interessantíssima relação de causa e efeito, pois embora soe óbvia, não necessariamente ocorrerá nesta ordem.

Deste modo, depreende-se destes conceitos uma equação simples, onde capacitação é a peça-chave para lograr êxito no exercício de suas funções, e, ainda, chegar a gozar do tão sonhado reconhecimento, que não se limita apenas ao nível pessoal, mas também do reconhecimento da marca como sendo referência em seu ramo de atuação (VIANNA, 2015).

Um programa de capacitação profissional faz-se essencial não apenas para que o indivíduo tenha extraído o melhor de si e possa enfim usufruir do tão sonhado reconhecimento, mas sim assume caráter de estratégia competitiva por influenciar diretamente na motivação dos colaboradores, de acordo com o que foi demonstrado no tópico posterior. 


\subsubsection{MOTIVAÇÃO COMO ESTRATÉGIA COMPETITIVA DAS ORGANIZAÇÕES}

Para Soares (2015) a motivação pode ser preceituada como sendo a influência para ensejar determinada conduta humana, dependendo do tipo de estímulo que for empregado, embora esta mesma força motriz seja intrínseca ao âmago de cada qual, aguardando apenas algum fator externo ou interno que enseje sua utilização.

O projeto não absolutamente ocorre para pleitear algum objetivo. Em tempo, considerando-se este viés, Soares dispõe que:

No momento em que uma pessoa toma a decisão de caminhar para alcançar um objetivo, não quer dizer que ela se encontra motivada completamente para fazer tal atividade, diversas vezes o ser humano só executa o ato pelo motivo de ser forçado, para impedir futuras correções de seus chefes, ou do mesmo modo por retribuições que sejam capazes de aparecer no momento em que tal objetivo é atingido. Porém, a iniciativa com o intuito de que a pessoa prossiga em definida direção não saiu completamente dela, mas sim de um terceiro, que proporcionou estímulos que a fez avançar e atingir tal objetivo.

Ainda sobre o que dispõe Soares (2015), a postura dos gestores está diretamente relacionada à motivação dos colaboradores que a estes forem subordinados. Ainda sobre o que dispõe a autora, é inóspito para a motivação o ambiente onde os funcionários só operem por medo de represálias, posto que o medo não pode ser considerado um modo de motivar, mas sim de coagir o funcionário a seguir os ditames que lhe forem ordenados.

A motivação impacta diretamente nos resultados de qualquer organização, posto que são consequências decorrentes dela o aumento da produtividade, redução do absenteísmo, melhoria nos indicadores de satisfação com o serviço prestado, dentre outros (SOARES, 2015). 
Partindo desta realidade de impactos positivos, é mister colocá-los como forma de diferenciação da concorrência, que culmina em ser extremamente acirrada dentro do contexto de uma sociedade globalizada. Destarte, a competitividade organizacional tende a ser cada vez mais fortificada ao passo que a empresa se torna referência pelos bons indicadores que foram supracitados (SOARES, 2015).

\section{MATERIAIS E MÉTODOS}

A Metodologia é a gnose que analisa métodos, deste modo, ela estabelece métodos próprios de investigação, estudo e pesquisa. Para isso, consideramos que o método científico é a teoria da investigação e que esta alcança seus objetivos, de forma científica, quando cumpre ou se propõe a cumprir as seguintes etapas (Silva, 2017)

Segundo Almeida (2017):

Um método científico pode ser definido como uma série de regras básicas, as quais devem ser executadas na geração de conhecimento que tem o intuito da ciência, isto é, um método é usado para a pesquisa e comprovação de um determinado assunto.

Consequentemente, no referido trabalho científico, adotou-se diferentes instrumentos, buscando assim, métodos e formas que auxiliem a detectar as resoluções mais adequada e eficientes aos gargalos já citados e expostos da M.D.A. Elevadores.

\subsection{PROCEDIMENTOS METODOLÓGICOS}

Os procedimentos metodológicos referem-se ao conjunto de tomada de decisões e ações quanto a escolha das técnicas de pesquisa e métodos utilizados para 0 crescimento do trabalho científico. Neste trabalho, optou-se pela coleta e administração de informações e dados da organização estudada, com o intuito de identificar os gargalos na estrutura e nos métodos para assim, efetivar ferramentas e tecnologias que aumentem a motivação dos colaboradores bem como a produtividade da M.D.A. Elevadores. 


\subsubsection{QUANTO À NATUREZA}

Quanto a natureza, a pesquisa podem ser básicas, aplicada. Quando básica tem o objetivo de gerar um conhecimento novo para a ciência. Segundo Lakatos (2017) "A pesquisa aplicada caracteriza-se por seu interesse prático, isto é, que os resultados aplicados ou utilizados, imediatamente, na solução de problemas que ocorrem na realidade."

Tendo em vista, o que foi dito acima, a natureza utilizada neste trabalho foi aplicativa, levando em consideração que o projeto pode ser utilizado na empresa. A pesquisa aplicada na organização correspondeu-se a abordagem quali-quantitativa, através de diálogos, coleta de dados e visitas possibilitando um cruzamento de conclusões.

\subsubsection{QUANTO AOS FINS}

Para Liane Carly Hermes (2013):

Como pesquisa, tem a finalidade de produzir conhecimento. E, por último, como extensão, permite que os estudantes, através de eventos diversos como consultorias, prestação de serviços, projetos de diagnóstico organizacional, entre outros, compartilhem com a comunidade externa 0 conhecimento produzido dentro da universidade.

Quantos aos fins, a pesquisa será qualitativa para ter uma percepção melhor com análises, tem como foco compreender melhor a visão do consumidor, estudando as experiências individuais.

\subsubsection{QUANTO AOS MEIOS}

Para Liane Carly Hermes (2013) "A pesquisa visa essencialmente a produção de novo conhecimento e tem a finalidade de buscar respostas a problemas e a indagações teóricas e práticas." 
Quanto ao projeto será baseou-se nas estatísticas, observando o comportamento do cliente, análise para se buscar uma estratégia adequada e alinhar os pensamentos da equipe para definição de um projeto e estratégia.

\subsection{CARACTERÍSTICAS DA EMPRESA}

A MDA elevadores consiste em uma empresa 100\% amazonense que se faz presente nos principais mercados da região norte, especializada em serviços de manutenção preventiva, assistência técnica e instalação de equipamentos com 12 anos de tradição assegurando qualidade e segurança aos seus usuários. A empresa possui 17 colaboradores e grande parte destes colaboradores são do gênero masculino, 1 apenas no sexo feminino com diferentes níveis de escolaridade. Seu faturamento de cinquenta mil reais e enquadra-se em pequena empresa, no entanto, na entrevista com 0 proprietário da empresa ele pretende aumentar significativamente seu rendimento, e ampliar suas unidades. Deste modo, a empresa tem como característica organizacional a departamentalização, ou seja, a segmentação por setores, definindo o enquadramento de cargos e serviços prestados, além de estabelecerem a divisão hierárquica tornado evidente as funções de seus colaboradores para facilitar o desempenho das atividades e agilizar os processos. Uma das principais atividades da empresa e tendo como característica exclusiva são os serviços prestados aos clientes como relatórios mensais das manutenções disponíveis com acesso online.

\section{RESULTADOS E DISCUSSÕES}

Mediante as pesquisas e estudos realizados durante processo do diagnóstico organizacional, foi possível constatar os pontos positivos e fundamentais da empresa estudada, assim, analisando cada área funcional. De modo a ser observado no gráfico 01. Medição de desempenho.

Gráfico 01: Medição por área funcional. 


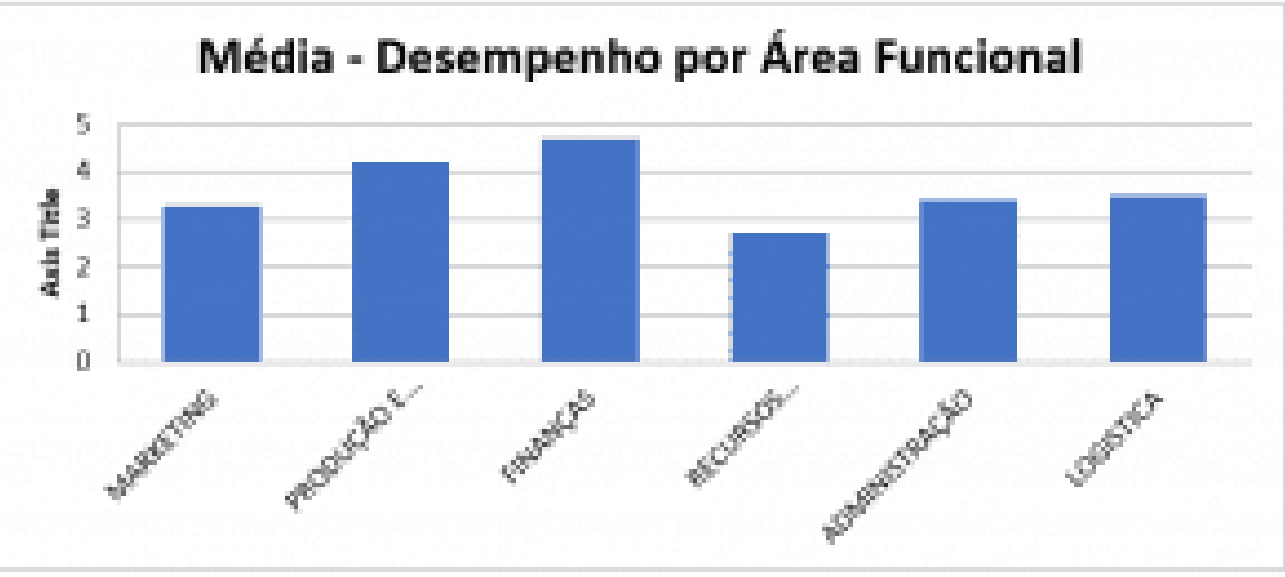

Fonte: elaborado por autores conforme coleta de dados, 2021.

Ao realizar análise do gráfico, verifica-se que a empresa apresenta os melhores índices nas áreas de finanças, produção e operação e administração. Enquanto a área de Recursos Humanos, apresenta a área mais crítica da empresa.

Quadro 01: Recursos humanos.

\begin{tabular}{|c|c|c|c|c|c|c|}
\hline \multirow{2}{*}{\multicolumn{2}{|c|}{$\begin{array}{l}\text { AREA FUNCIONAL } \\
\text { RECURSOS HUMANOS }\end{array}$}} & \multicolumn{5}{|c|}{ NÍVEL OU GRAU DE AVALIAÇÃO } \\
\hline & & $\begin{array}{l}\text { Ponto } \\
\text { muito } \\
\text { forte } \\
5\end{array}$ & $\begin{array}{l}\text { Ponto } \\
\text { forte } \\
4\end{array}$ & $\begin{array}{l}\text { Ponto } \\
\text { médio } \\
3\end{array}$ & $\begin{array}{l}\text { Ponto } \\
\text { fraco } \\
2\end{array}$ & $\begin{array}{l}\text { Ponto } \\
\text { muito } \\
\text { fraco } 1\end{array}$ \\
\hline 1 & $\begin{array}{l}\text { Destaca-se pelo investimento } \\
\text { constante na capacitação das } \\
\text { equipes funcionais }\end{array}$ & & & $\mathbf{x}$ & & \\
\hline 2 & $\begin{array}{l}\text { Registra-se um quadro de } \\
\text { colaboradores totalmente } \\
\text { legalizado nos padrões da } \\
\text { CLT }\end{array}$ & $\mathbf{x}$ & & & & \\
\hline 3 & $\begin{array}{lr}\text { Observa-se } & \text { correto } \\
\text { investimento } & \text { em }\end{array}$ & & & & $\mathbf{x}$ & \\
\hline
\end{tabular}

RC: 101786

Disponível em: https://www.nucleodoconhecimento.com.br/administracao/fator$\underline{\text { motivacional }}$ 


\begin{tabular}{|c|c|c|c|c|c|c|}
\hline & $\begin{array}{l}\text { equipamentos de proteção } \\
\text { individual }\end{array}$ & & & & & \\
\hline 4 & $\begin{array}{lr}\text { Evidenciam-se } & \text { políticas } \\
\text { organizacionais } & \text { que } \\
\text { incentivem os colaboradores }\end{array}$ & & & & $\mathbf{x}$ & \\
\hline 5 & $\begin{array}{l}\text { Observa-se que política de } \\
\text { benefícios e uma ferramenta } \\
\text { de retenção do capital } \\
\text { intelectual }\end{array}$ & & & & $\mathbf{x}$ & \\
\hline 6 & $\begin{array}{l}\text { Observa-se introdução de } \\
\text { novos conhecimentos e } \\
\text { capacitação interna }\end{array}$ & & & & & $\mathbf{x}$ \\
\hline 7 & $\begin{array}{l}\text { Percebe-se política salarial, } \\
\text { benefícios, higiene } \\
\text { segurança interna como } \\
\text { diferencial }\end{array}$ & & $\mathbf{x}$ & & & \\
\hline 8 & $\begin{array}{l}\text { Analisa-se a produtividade } \\
\text { individual dos técnicos }\end{array}$ & & $\mathbf{x}$ & & & \\
\hline 9 & $\begin{array}{l}\text { Nota-se preocupação com a } \\
\text { saúde ocupacional dos } \\
\text { colaboradores }\end{array}$ & & & & & $\mathbf{x}$ \\
\hline 10 & $\begin{array}{l}\text { Compreende-se que todos os } \\
\text { colaboradores são } \\
\text { responsáveis pelos } \\
\text { resultados operacionais }\end{array}$ & & & $\mathbf{x}$ & & \\
\hline \multicolumn{2}{|r|}{ TOTAL $(\Sigma)$} & 5 & 8 & 6 & 6 & 2 \\
\hline \multicolumn{2}{|r|}{ MÉDIA POR GRAU (POR COLUNA) } & 0,5 & 0,8 & 0,6 & 0,6 & 0,2 \\
\hline \multicolumn{2}{|r|}{ DESEMPENHO DA ÁREA } & 2,7 & & & & \\
\hline
\end{tabular}

Fonte: elaborado por autores conforme coleta de dados, 2021. 
De acordo com os fatores críticos expostos no quadro 01 , identificam-se pontos pertinentes na área de recursos humanos na M.D.A Elevadores, estes, são de extrema importância para o aumento da produtividade e desenvolvimento da empresa frente a um mercado tão competitivo, visto que refletem diretamente na motivação dos colaboradores. Deste modo se faz necessário a resolução desta problemática: Como o processo de desenvolvimento pessoal pode contribuir com a melhoria da motivação das equipes funcionais?

\subsection{PLANEJAMENTO DE AÇÕES}

A programação das ações, consiste em dividir a ação em uma quantidade de passos, descrevendo como deve-se atuar perante a estratégia, para que dessa forma, possa encaminhar a organização no caminho que proporcione a conquista das metas delineadas por ela.

Quadro 02 - Ações Interventivas

\begin{tabular}{|c|c|c|c|c|}
\hline & Ações Interventivas & Cronologia & Duração & Custo \\
\hline 1 & $\begin{array}{l}\text { Mapear os processos de trabalho da } \\
\text { empresa }\end{array}$ & $\begin{array}{l}\text { Setembro } \\
2021\end{array}$ & $\begin{array}{l}\text { Uma vez na } \\
\text { semana }\end{array}$ & $\begin{array}{l}\mathrm{R} \$ \\
350,00\end{array}$ \\
\hline 2 & $\begin{array}{l}\text { Estruturar um plano de treinamento } \\
\text { voltado para a tomada de decisões }\end{array}$ & $\begin{array}{l}\text { Setembro } \\
2021\end{array}$ & $\begin{array}{l}\text { Duas vezes } \\
\text { na semana }\end{array}$ & $\begin{array}{l}\mathrm{R} \$ \\
500,00\end{array}$ \\
\hline 3 & $\begin{array}{l}\text { Palestra sobre a importância do } \\
\text { planejamento }\end{array}$ & $\begin{array}{l}\text { Setembro } \\
2021\end{array}$ & 2 dias & $\begin{array}{l}\mathrm{R} \$ \\
1.000,00\end{array}$ \\
\hline 4 & $\begin{array}{l}\text { Estruturar um plano de ação voltada } \\
\text { para a melhoria do atendimento ao } \\
\text { cliente }\end{array}$ & $\begin{array}{l}\text { Setembro } \\
2021\end{array}$ & 4 dias & $\begin{array}{l}\mathrm{R} \$ \\
600,00\end{array}$ \\
\hline 5 & $\begin{array}{l}\text { Estabelecer parcerias estratégicas de } \\
\text { suprimentos com seus fornecedores }\end{array}$ & $\begin{array}{l}\text { Setembro } \\
2021\end{array}$ & 5 dias & $\begin{array}{l}\mathrm{R} \$ \\
2.000,00\end{array}$ \\
\hline 6 & $\begin{array}{l}\text { Estruturar o controle de custos } \\
\text { logísticos em relação aos serviços }\end{array}$ & $\begin{array}{l}\text { Setembro } \\
2021\end{array}$ & $\begin{array}{l}\text { Uma vez na } \\
\text { semana }\end{array}$ & $\begin{array}{l}\mathrm{R} \$ \\
350,00\end{array}$ \\
\hline
\end{tabular}

RC: 101786

Disponível em: https://www.nucleodoconhecimento.com.br/administracao/fatormotivacional 
prestados

7 Treinamento voltado ao conhecimento Setembro 2 dias $\mathrm{R} \$$ técnico das peças utilizadas na 2021 instalação dos produtos

TOTAL

Fonte: elaborado por autores conforme coleta de dados, 2021.

A proposta acima foi desenvolvida por meio de quadros de ações interventivas, adotando-se a ferramenta $5 \mathrm{~W} 2 \mathrm{H}$, está que é um instrumento planejamento, introdução e controle das ações. De forma que fique bem claro como, em quanto tempo será feito e por quem será feito.

Segundo Gomes (2014) "5W2H é uma ferramenta para elaboração de planos de ação que, por sua simplicidade, objetividade e orientação à ação, tem sido muito utilizada em Gestão de Projetos, Análise de Negócios, Elaboração de Planos de Negócio, Planejamento Estratégico e outros pontos importantes para o auxílio de gestão".

Ao utilizar esta ferramenta, busca-se propiciar maneiras de alinhar o que foi planejado com o que está sendo executado, até que ambos estejam funcionando.

\subsubsection{MAPEAR OS PROCESSOS DE TRABALHO DA EMPRESA}

Para esta atividade, será necessária a ação conjunta do setor de $\mathrm{RH}$ e administrativo, juntamente com o operacional, acompanhando e vivenciando o dia a dia, de todos os funcionários envolvidos no processo produtivo, de modo que ele mapeie e averigue os níveis de dificuldades, a implementação e o tempo de realização de cada etapa do processo, após o acompanhamento será necessário desenvolver o fluxograma. 
Segundo Maranhão e Macieira (2010, p. 251) definem como sendo fluxograma uma figura feita com símbolos padronizados e textos devidamente arrumados a fim de mostrar sequência lógica de passos de realização dos processos ou atividades. Completam dizendo que a visualização gráfica é sempre um poderoso canal de comunicação, por ser mais bem absorvida e de maior compreensão do que os textos escritos, que exigem esforço mental e são mais subjetivos. está é a forma mais eficiente de detectar os gargalos do processo e fazer as melhorias necessárias.

Quadro 03: 5W2H - Mapear os processos de trabalho na empresa.

Mapear os processos de trabalho da empresa

O que? Mapear os processos

Por quê? Para melhor compreensão do processo produtivo

Onde? Na M.D.A Elevadores

Quando? Primeira Semana de Setembro de 2021

Quem? Setor de RH/Administrativo e setor de operações

Como? O responsável do setor de Rh acompanhará o dia a dia do setor de operações afim de identificar os gargalos e aperfeiçoar os processos, através do desenvolvimento de um fluxograma.

Quanto? R\$350,00

Fonte: elaborado pelas autoras, 2021.

Ao mapear e construir o fluxograma do processo produtivo da empresa, é possível detectar, os pontos a serem melhorados dentro deste processo, tendo em vista que o fluxograma, apresenta de forma gráfica, todos as etapas, de forma simplificada. Por isso é importante a interação tanto de quem está na linha de frente, atuando no processo, tanto do profissional do nível estratégico que será o responsável por transformar o que observou em dados. Com estes dados em mãos, é o momento de identificar os gargalos e resolvê-los. 


\subsubsection{ESTRUTURAR PLANO DE TREINAMENTO VOLTADO PARA A TOMADA DE DECISÕES}

Depois do mapeamento dos processos produtivos, torna-se mais claro para todas as áreas funcionais, como funciona o processo produtivo e quais são as disfunções encontradas, desta forma, os gerentes devem mapear quais os setores necessitam de treinamento, estudando assim, qual tipo de treinamento deve ser aplicado e para quem deve ser aplicado. Por meio do L.N.T (Levantamento de necessidade de treinamento), este levantamento, consiste no estudo da situação da empresa, seu foco, seu perfil considerando as causas das suas adversidades, os processos que apresentam falhas, tendendo na decisão da melhor forma de melhorar o desempenho.

Quadro 04: $5 \mathrm{~W} 2 \mathrm{H}$ - Estruturar o plano de treinamento voltado para a tomada de decisões

\section{Estruturar um plano de treinamento voltado para a tomada de decisões}

O que? Estruturar um plano de treinamento

Por quê? Para começar o processo de descentralização

Onde? Na M.D.A Elevadores

Quando? Na primeira semana de Setembro de 2021.

Quem? Gerente do RH e Gerente de operações

Como? Mapear por meio levantamento de necessidades de treinamento (LNT) os setores que precisam de treinamento, através da identificação dos gargalos e pontos de melhoria.

Quanto? $\mathrm{R} \$ 500,00$

Fonte: elaborado pelas autoras, 2021.

Levantamento de necessidades de treinamento (L.N.T) poderá ser feito através dos diagnósticos setoriais e através do mapeamento dos processos o identificando as 
competências necessárias para cada posto de trabalho buscando identificar quais competências individuais e coletivas precisam ser desenvolvidas na equipe.

Ao adotar-se esta ação objetiva-se direcionar o plano de desenvolvimento, pois o levantamento de treinamento identifica quais colaboradores precisam passar por treinamentos e quais as competências devem ser priorizadas, desta forma, é possível evitar treinamentos desnecessários, que gerem altos custos e poucos resultados. Ou seja, esta ferramenta pretende viabilizar para a organização, a escolha do treinamento mais proveitoso para as necessidades da empresa.

\subsubsection{PALESTRA SOBRE A IMPORTÂNCIA DO PLANEJAMENTO ESTRATÉGICO}

Deve ser ministrada uma apresentação sobre a importância do planejamento estratégico a todos os colaboradores da organização, durante o processo de descentralização é de suma importância que todos os colaboradores pensem estrategicamente, para que estes contribuam na tomada de decisões, deixando assim, os processos mais fluídos e menos engessados. Recomenda-se um treinamento no modelo de mentoria, ou seja, um colaborador experiente da empresa, poderá ministrar o assunto, qual ele domina, para os demais colaboradores. Este tipo de projeto, é muito indicado para empresas de pequeno porte, tendo em vista, o seu custo-benefício.

Quadro 05: 5W2H - Palestra sobre a importância do planejamento.

Palestra sobre a importância do planejamento

\begin{tabular}{l|l} 
O que? & Palestra \\
\hline Por quê? & $\begin{array}{l}\text { Para que todos os colaboradores compreendam a importância de um } \\
\text { bom planejamento }\end{array}$ \\
\hline Onde? & Na M.D.A Elevadores \\
\hline Quando? & Na segunda semana de Setembro de 2021. \\
\hline Quem? & Gerente do RH
\end{tabular}


Como? Mediante a uma reunião com todos os colaboradores, onde será explanado a importância do planejamento.

Quanto? $R \$ 2.000,00$

Fonte: elaborado pelas autoras, 2021.

Escolheu-se apresentar a palestra para todos os colaboradores da organização, porque o planejamento estratégico funciona basicamente como um plano de viagem, descrevendo onde a empresa quer chegar e qual caminho ela percorrerá para alcançar o destino, além de auxiliar a compreensão das mudanças do ambiente externo e interno.

Contudo, é de suma importância, compartilhar e enfatizar a importância do planejamento estratégico, além de vender a ideia, é necessário que os colaboradores se sintam protagonistas da execução dela. Espera-se a compreensão dos colaboradores de que quanto mais a empresa crescer, mais desenvolvidos e bem remunerados eles serão.

\subsubsection{ESTRUTURAR UM PLANO DE AÇÃO VOLTADO A MELHORIA DO ATENDIMENTO AO CLIENTE}

Deve-se fazer uma pesquisa quali-quantitativa com os clientes da organização M.D.A Elevadores, a fim de detectar quais são os pontos de melhorias, indicados por eles, dessa forma, torna-se possível trabalhar em cima dos gargalos do atendimento ao cliente. Corrigindo as disfunções apontadas pelo cliente-alvo da M.D.A., fortalecemos a imagem da marca no mercado.

Quadro 06: 5W2H - Estruturar plano de ação voltado a melhoria no atendimento.

Estruturar um plano de ação voltado a melhoria do atendimento ao cliente.

O que? Elaborar um plano de ação para melhoria do atendimento

Por quê? Fortalecer a marca, através de uma boa avaliação dos clientes internos 
e externos,

Onde? Na M.D.A Elevadores

Quando? Na segunda semana de setembro de 2021.

Quem? Gerente do setor comercial

Como? Através de uma pesquisa de satisfação, detectar quais são os pontos de melhorias, indicados pelos clientes. Após a apuração, passar para os profissionais que lidam diretamente com os clientes, os pontos a serem melhorados.

Quanto? R\$600,00

Fonte: elaborado pelas autoras, 2021.

Com esta ação espera-se feedback do público externo da M.D.A, a respeito das disfunções do atendimento. A partir do mapeamento dos resultados do feedback a empresa poderá gerenciar a efetividade nos treinamentos implementados e aperfeiçoar os processos de treinamento e desenvolvimento orientando-se pelo mercado externo e suas demandas. Neste mercado tão competitivo, agradar o cliente, oferecendo um atendimento diferenciado torna-se uma vantagem competitiva, de modo que a empresa se destaque frente aos seus concorrentes.

\subsubsection{ESTABELECER PARCERIAS ESTRATÉGICAS DE SUPRIMENTOS COM SEUS FORNECEDORES}

Para manter-se competitiva no mercado, faz-se necessário apresentar diferenciais competitivos para cativar o cliente, uma alternativa já utilizada e qual gostaríamos que fosse fortalecida, é o B2B com os fornecedores de suprimentos. Para que este networking seja colocado em prática, primeiro deverá ser executada uma pesquisa de mercado, a fim de encontrar os fornecedores de suprimentos de elevadores e escadas rolantes, após essa apuração, o gerente comercial deverá marcar uma reunião com os representantes, para que essa parceria possa ser fechada, fortalecendo ambas as marcas no mercado quais estão inseridas. 
Quadro 07: 5W2H - Estabelecer parcerias estratégicas com os fornecedores.

\section{Estabelecer parcerias estratégicas de suprimentos com seus fornecedores}

O que? Estabelecer parcerias estratégicas

Por quê? Através de um bom networking, a empresa se fortalece e oferece diferencial competitivo.

Onde? Na M.D.A Elevadores

Quando? Na terceira semana de setembro de 2021.

Quem? Gerente do setor comercial

Como? Através de uma pesquisa de mercado, mapear os principais fornecedores de suprimentos; marcar uma reunião para que seja possível apresentar as vantagens dessa negociação B2B.

Quanto? R\$2.000,00

Fonte: elaborado pelas autoras, 2021.

As parcerias estratégicas são fundamentais neste seguimento estudado, pois e impossível manter peças sobressalentes para todos os componentes que podem ser danificados. A falta de componentes atrasa o tempo de execução das tarefas de manutenção e consequentemente proporcionam enorme desconforto no relacionamento das equipes de manutenção e os clientes.

Espera-se que com o estabelecimento de parcerias o tempo de execução dos serviços seja reduzido proporcionando maior produtividade das equipes e maior satisfação dos clientes

\subsubsection{ESTRUTURAR O CONTROLE DE CUSTOS LOGÍSTICOS EM RELAÇÃO AOS SERVIÇOS PRESTADOS}

Deverá ser efetuada uma pesquisa com os diversos meios de transportes utilizados no país, a fim de cotar e fechar o menor valor, tendo em vista que ao diminuir os custos automaticamente maximizam-se os lucros. 
Quadro 08: 5W2H - Estruturar controle de custos logísticos

Estruturar o controle de custos logísticos em relação aos serviços prestados

O que? Estruturar controle de custos logísticos

Por quê? Maximizar os lucros, diminuindo os custos

Onde? Na M.D.A Elevadores

Quando? Na terceira semana de setembro de 2021.

Quem? Gerente financeiro e Gerente de Operações

Como? Através de uma pesquisa de mercado, cotar com os diversos meios de transportes, a fim de diminuir os custos.

Quanto? R\$350,00

Fonte: elaborado pelas autoras, 2021.

Esta se torna também e fundamental, pois os parceiros fornecedores estão alocados em outras cidades sendo necessário ter antecipadamente as estratégias de transportes definidas e transportadores qualificados e homologados para execução dos serviços.

Com esta ação espera-se reduzir o custo operacional e também o tempo de suprimento dos componentes.

\subsubsection{TREINAMENTO VOLTADO AO CONHECIMENTO TÉCNICO DAS PEÇAS UTILIZADAS PARA INSTALAÇÃO DOS PRODUTOS}

Este treinamento deverá ser ministrado pelo técnico operacional, para todos os colaboradores que trabalham no setor operacional, na instalação e manutenção dos produtos, este treinamento tem 0 intuito de melhorar 0 atendimento ao cliente, levando em consideração que quanto maior o conhecimento técnico da equipe mais rápido é o tempo de resposta frente aos impasses do processo, melhorando o tempo de instalação e aumentando o grau de satisfação do cliente. 
Quadro 09: 5W2H - Treinamento técnico das peças utilizadas na instalação dos produtos.

Treinamento voltado ao conhecimento técnico das peças utilizadas para instalação dos produtos

O que? Treinamento

Por quê? Agregar valor e conhecimento a equipe

Onde? Na M.D.A Elevadores

Quando? Na quarta semana de setembro de 2021.

Quem? Técnico operacional

Como? Será ministrado um treinamento a respeito das peças utilizadas na instalação dos produtos comercializados pela M.D.A.

Quanto? R\$1.000,00

Fonte: elaborado pelas autoras, 2021.

Esta ação visa enriquecer e fortalecer a equipe operacional da organização, treinamentos que geram conhecimentos técnicos, otimizam as rotinas, reduzem a rotatividade, motivam e aumentam a produtividade. Promovem o desenvolvimento dos planos de carreira e salários, além de proporcionar maior oxigenação para o ambiente de trabalho.

\section{CONSIDERAÇÕES FINAIS}

A MDA elevadores é empresa amazonense de tradição do ramo de elevadores, especializada em serviços de manutenção preventiva, assistência técnica e instalação de equipamentos, está presente na região norte, conta com uma equipe de 17 funcionários e encaixa-se em pequena empresa.

A partir dos resultados identificados no diagnostico organizacional realizado na empresa observou-se que a empresas precisava aperfeiçoar seus processos 
relativos ao atendimento por meio do maior engajamento de suas equipes operacionais.

Como reposta ao contexto apresentado orientou-se estudo de caso pela seguinte pergunta problema: Como o processo de desenvolvimento pessoal pode contribuir com a melhoria da motivação das equipes funcionais? Para solucionar o problema de pesquisa primeira orientação demostrada para o avanço do índice referente aos recursos humanos é a atividade de mapear os processos de trabalho da empresa, ação essa desenvolvida pelos setores de $\mathrm{RH}$ e administrativo em parceria com o operacional para acompanhar a rotina dos colaboradores e mapear as dificuldades existentes, assim como o tempo dos processos e etapas para o avanço um fluxograma dos processos facilitando assim para os colaboradores atuais e futuros. Em seguida é demonstrada a importância de estruturar plano de treinamento voltado para a tomada de decisões, perguntas simples apresentadas no quadro 04 que podem tornar tomadas de medidas ágeis e eficazes por meio do uso do método (L.N.T.) levantamento de necessidades de treinamento diagnosticado pelo mapeamento dos processos.

Destacou-se que introduzir palestras sobre a importância do planejamento estratégico, assim como um treinamento de mentoria para um colaborador experiente e conhecedor da empresa ministrar aos outros. Estruturar um plano de ação voltado a melhoria do atendimento ao cliente, além de estabelecer parcerias estratégicas de suprimentos com seus fornecedores, estruturar o controle de custos logísticos em relação aos serviços prestados e o presente artigo finaliza as indicando o treinamento voltando ao conhecimento técnico das peças utilizadas para a instalação dos produtos.

Em suma através das pesquisas que constataram pontos que necessitavam melhorias usando estratégias e planos de ações, foi apresentado diversos tópicos que evidenciam pontos possíveis de aperfeiçoamentos, elevando o nível da empresa em todos os aspectos. 


\section{REFERÊNCIAS}

AIMEIDA, M. B. Noções básicas sobre Metodologia de pesquisa científica. Univer- sidade Federal de Minas Gerais. Disponível em <http://mba.eci.ufmg.br/down- loads/metodologia.pdf>. Acesso em 26 ago. 2017.

CHIAVENATO, Idalberto. Introdução a Teoria Geral da Administração. 9 Ed. Rev. Atual. São Paulo: Monele LTDA, 2014.

CHIAVENATO, Idalberto. Gestão de pessoas: o novo papel dos recursos humanos nas organizações. 4. ed. Barueri- Sp, 2014.

DE LARA, Marcos Batista; ROSA, Solange Martins. Estudo de caso - A descentralização da área de recursos humanos, sob a perspectiva dos colaboradores, em uma empresa do ramo alimentício no Vale do Paranhana. Revista de Administração de Empresas Eletrônica. № 2. 2015. Disponível em: <https://seer.faccat.br/index.php/administracao/article/view/309>. Acesso em 24 de Setembro de 2021.

FERNANDES, Bruno Henrique Rocha. Gestão estratégica de pessoas com foco em competência. 1. ed. Rio de Janeiro, 2013.

GIL, Antônio Carlos. Gestão de pessoas: enfoque nos papéis profissionais. São Paulo: Atlas, 2014.

GOMES, Luciano 5W2H: Ferramenta para a elaboração de Planos de Ação disponível em: http://blog.iprocess.com.br/2014/06/5w2h-ferramenta-para-aelaboracao-de-planos-de-acao/ acesso em: 28/04/2015

LAKATOS, Eva. M.; Marconi, Marina A. Metodologia científica. São Paulo: Atlas, 1991

LORENTZ, Cacilda. Reflexões sobre Reconhecimento no Trabalho. Universidade FUMEC. Artigos CIPA. 2014. Disponível em: 
$<$ http://www.fumec.br/anexos/servicos/professor/cipa/Cacilda-Lorentz.pdf>. Acesso em 24 de Setembro de 2021.

MARANHÃO, M.; MACIEIRA, B. E. M. O processo nosso de cada dia, modelagem de processos de trabalho. Rio de Janeiro: Qualitymark, 2010.

MAXIMIANO, A. A. Fundamentos de administração: introdução à teoria geral e aos processos da administração. 3. ed. Rio de Janeiro: LTC, 2015.

Teoria geral da Administração: da revolução urbana à revolução digital. 7. ed. São Paulo: Atlas, 2012.

MCLEAN, P.; Hudson, F. (2012). "The completely revised handbook of coaching: a developmental approach". Jossey Bass: a wiley imprint - 2a edição.

Passmore, J.; Peterson, D.B.; Freire, T. (2013). "Handbook of the psychology of coaching and mentoring". The Wiley: Blackwell - 1a edição.

SANTOS, Clezio Saldanha dos. Introdução à Gestão Pública. 2. ed. São Paulo: Saraiva, 2014.

SOARES, Bruna Caroline Moreira. Motivação nas Organizações. Monografia. Bacharelado em Administração. Fundação Educacional do Município de Assis. 2015. Disponível em: <https://cepein.femanet.com.br/BDigital/arqTccs/1211390795.pdf>. Acesso em 25 de Setembro de 2021.

TACHIZAWA, T. Gestão com pessoas: uma abordagem aplicada às estratégias de negócios. Editora FGV, 2015

VERGARA, Sylvia Constant. Gestão de Pessoas. 9 Ed. São Paulo: Atlas, 2010.

VIANNA, Vânia Alves. Elaboração de planos de capacitação. Brasília: Escola Nacional de Administração Pública. 2015. Disponível em: 
$<$ https://repositorio.enap.gov.br/bitstream/1/2383/1/Apostila\%26CE_EPC_rev_final_2 4-11-15.pdf>. Acesso em 24 de Setembro de 2021.

Enviado: Outubro, 2021.

Aprovado: Novembro, 2021. 